\title{
Institutional Professional Consultation
}

National Cancer Institute

\section{Source}

National Cancer Institute. Institutional Professional Consultation. NCI Thesaurus. Code C150762.

A patient encounter with a healthcare professional for a medical consultation. 